\title{
ANALISIS FAKTOR-FAKTOR YANG MEMPENGARUHI PRODUKTIVITAS PEMANEN KELAPA SAWIT \\ (Kasus Pada PT Socfin Indonesia Perkebunan Aek Loba Kecamatan Aek Kwasan dan Kecamatan Pulau Rakyat Kabupaten Asahan Provinsi Sumatera Utara)
}

\author{
Sriyoto \\ Andi Irawan \\ Kianditara \\ Jurusan Sosial Ekonomi Pertanian Fakultas Pertanian Universitas Bengkulu
}

\begin{abstract}
This research was aimed to know the productivity level of palm fruit harvesting labours and to know the productivity influence factors of palm fruit harvesting labours at Socfin Indonesia Company Aek Loba Plantation. Productivity of man power was calculated by using productivity analysis and to identify factors influencing the productivity of palm fruit harvesting labours at Socfin Indonesia Company Aek Loba Plantation. Eighty seven respondent selected using simple random sampling and data were analyzed using double linear regression analysis. Result of this research show the productivity of palm fruit harvesting labours at Socfin Indonesia Company Aek Loba Plantation still in lower category, with range of 93,05 - 1884,8 and an average of 759,04 $\mathrm{Kg} /$ days. The estimation result show that age, work experiences and family amount responsibility variable have the positive influences to the productivity of palm fruit harvesting labours. Its means that the premi perceptions and work motivation has no real influence to the productivity of palm fruit harvesting labours.
\end{abstract}

Keyword: palm oil, productivity of man power, Socfin Indonesia

\section{PENDAHULUAN}

Produktivitas tenaga kerja merupakan perbandingan antara produk yang dihasilkan dengan tenaga kerja yang dipergunakan untuk menghasilkan produk tersebut dalam waktu tertentu. Menurut Indrawati et al (1999), produktivitas tenaga kerja manusia tergantung pada kemampuan dan kemauan setiap orang. Dalam hal ini, kemampuan mengacu pada kemampuan fisik serta tingkat pendidikan, pelatihan dan pengalaman, sedangkan faktor kemauan mengacu pada etos kerja, mentalitas, dan motivasi. Fadholi seperti dikutip Mardiana (2001) mengatakan produktivitas tenaga kerja dipengaruhi oleh umur, pengalaman, pendidikan, keterampilan, tingkat kecukupan, tingkat kesehatan dan faktor alam seperti iklim dan lahan usaha. 
PT Socfindo merupakan salah satu perusahaan perkebunan kelapa sawit dan karet yang berada di Propinsi Sumatera Utara. Pada penelitian kali ini, peneliti tertarik untuk meneliti produktivitas tenaga kerja yang digunakan untuk tanaman kelapa sawit di Perkebunan Aek Loba. PT Socfindo banyak mempekerjakan tenaga kerja pada kegiatan produksinya untuk kegiatan memanen buah kelapa sawit. Untuk mencapai produksi yang tinggi, tentunya produktivitas pemanen kelapa sawit menjadi faktor penting. Untuk itu penulis tertarik untuk mengetahui faktorfaktor apa saja yang mempengaruhi produktivitas pemanen kelapa sawit di PT Socfindo Perkebunan Aek Loba.

\section{METODOLOGI PENELITIAN}

Penelitian ini dilaksanakan di PT Socfin Indonesia (Socfindo) Perkebunan Aek Loba, Kecamatan Aek Kwasan dan Kecamatan Pulau Rakyat, Kabupaten Asahan, Propinsi Sumatera Utara yang dilaksanakan pada tanggal 24 September-6 Oktober 2007. Penentuan sampel pada penelitian ini dengan menggunakan metode simple random sampling. Sampel yang diambil sebesar $25 \%$ dari tiap unit populasi. Sehingga diperoleh sampel sebanyak 87 orang.

Untuk melihat kategori umur, pengalaman kerja dan jumlah tanggungan keluarga dengan menggunakan perhitungan standar deviasi, secara matematis dapat ditulis sebagai berikut :

$$
\begin{aligned}
& \mathrm{x}>(\bar{x}+1 / 2 \mathrm{SD})=\text { Tua/ Tinggi/ Banyak } \\
& (\bar{x}-1 / 2 \mathrm{SD}) \leq \mathrm{x} \leq(\bar{x}+1 / 2 \mathrm{SD})=\text { Sedang } \\
& \mathrm{x}<(\bar{x}-1 / 2 \mathrm{SD})=\text { Muda/ Rendah/ Sedikit }
\end{aligned}
$$

Menurut Umar (2003), untuk mengetahui produktivitas tenaga kerja digunakan rumus:

$$
\text { Produktivitas }=\frac{\text { Jumlah hasil panen setelah standar basis }(\mathrm{kg})}{\text { Jumlah hari kerja (hari) }}
$$

Alat analisis yang akan digunakan dalam menganalisis faktor-faktor yang mempengaruhi produktivitas pemanen kelapa sawit adalah analisis regresi linier berganda. Secara matematis dirumuskan dalam persamaan berikut: 


$$
Y=\beta_{0}+\beta_{1} X_{1}+\beta_{2} X_{2}+\beta_{3} X_{3}+\beta_{4} D_{1}+\beta_{5} D_{2}+e
$$

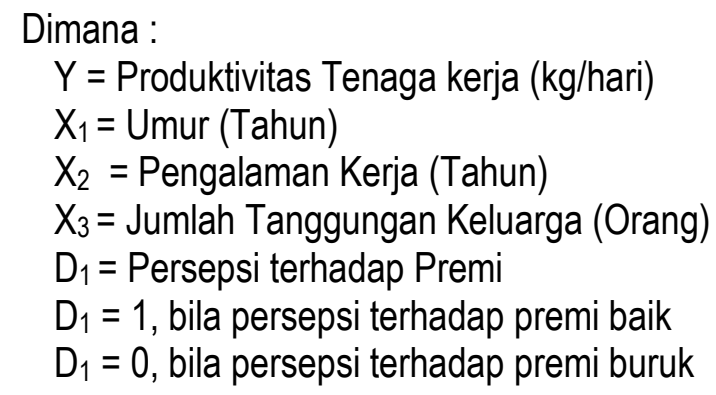

Dimana:

Persepsi baik jika total skor > rata-rata total skor

Persepsi buruk jika total skor $\leq$ rata-rata total skor

$D_{2}=$ Motivasi Kerja

$\mathrm{D}_{2}=1$, bila motivasi kerja tinggi

$D_{2}=0$, bila motivasi kerja rendah

Dimana:

Motivasi tinggi jika total skor > rata-rata total skor

Motivasi rendah jika total skor $\leq$ rata-rata total skor

$\mathrm{B}_{0}=$ Konstanta

$\beta_{1}-\beta_{5}=$ Koefisien regresi

$\mathrm{e}=$ Kesalahan pengganggu

Untuk mengetahui apakah secara bersama-sama variabel bebas (umur, pengalaman kerja, jumlah tanggungan keluarga, persepsi terhadap premi dan motivasi kerja) berpengaruh terhadap variabel terikat (produktivitas), maka dilakukan uji hipotesis yaitu dengan menggunakan uji F pada tingkat kepercayaan $95 \%$.

\section{HASIL DAN PEMBAHASAN}

\section{Umur}

Umur pemanen kelapa sawit akan mempengaruhi aktivitas kerja dari tenaga kerja tersebut. Pemanen kelapa sawit yang tergolong usia produktif akan mampu bekerja secara optimal dari pada orang yang tergolong belum atau tidak produktif. Menurut Tohir (1993), angkatan kerja digolongkan menjadi usia produktif yaitu 15 tahun sampai 50 tahun, usia belum produktif di bawah 15 tahun dan usia tidak produktif di atas 50 tahun.

Tabel 1 menunjukkan bahwa umur pemanen kelapa sawit di PT Socfindo Perkebunan Aek Loba berada pada kisaran 21 - 47 tahun dengan rata-rata 35,08 tahun dan persentase 
terbesar pada kategori umur muda yaitu sebanyak 34 orang atau sebesar 39,08 . Hal ini menunjukkan bahwa pemanen kelapa sawit tersebut berada pada golongan usia produktif. Kategori umur tua produktivitas rata-rata sebesar $1262,14 \mathrm{~kg} / \mathrm{hr}$, pada kategori umur sedang produktivitas rata-ratanya sebesar $701,27 \mathrm{~kg} / \mathrm{hr}$ dan kategori umur muda produktivitas rata-ratanya sebesar 469,68 kg/hr.

Tabel 1. Umur Pemanen Kelapa Sawit

\begin{tabular}{lcccccc}
\hline Kategori & $\begin{array}{c}\text { Kelompok umur } \\
\text { (th) }\end{array}$ & $\begin{array}{c}\text { Jumlah } \\
\text { (org) }\end{array}$ & $\begin{array}{c}\text { Kisaran } \\
\text { (th) }\end{array}$ & $\begin{array}{c}\text { Rerata } \\
\text { (th) }\end{array}$ & $\begin{array}{c}\text { Persentase } \\
(\%)\end{array}$ & $\begin{array}{c}\text { Produktivitas } \\
\text { Rerata (kg/hr) }\end{array}$ \\
\hline Tua & $(X>38,01)$ & 23 & & & 26,43 & 1262,14 \\
Sedang & $(32,15 \leq X \leq 38,01)$ & 30 & $21-47$ & 35,08 & 34,48 & 701,27 \\
Muda & $(X<32,15)$ & 34 & & & 39,08 & 469,68 \\
\hline & Jumlah & 87 & - & - & 100 & - \\
\hline
\end{tabular}

Sumber : Data Primer Diolah, 2007.

\section{Pendidikan Formal}

Tingkat pendidikan akan menentukan pola pikir seseorang serta akan menunjukkan tindakan dan sikap seseorang serta mempengaruhi kemampuan seseorang dalam menyerap inovasi-inovasi baru yang ada.

Tabel 2. Pendidikan Formal Pemanen Kelapa Sawit

\begin{tabular}{ccccccc}
\hline $\begin{array}{c}\text { Kategor } \\
\text { i }\end{array}$ & $\begin{array}{c}\text { Lama Pendidikan } \\
\text { (th) }\end{array}$ & $\begin{array}{c}\text { Jumlah } \\
\text { (org) }\end{array}$ & $\begin{array}{c}\text { Kisaran } \\
\text { (th) }\end{array}$ & $\begin{array}{c}\text { Rerata } \\
\text { (th) }\end{array}$ & $\begin{array}{c}\text { Persentase } \\
(\%)\end{array}$ & $\begin{array}{c}\text { Produktivitas } \\
\text { Rerata (kg/hr) }\end{array}$ \\
\hline Tinggi & $(X>9)$ & 12 & & & 13,79 & 572,26 \\
Sedang & $(6,82 \leq X \leq 9)$ & 31 & $6-12$ & 7,9 & 35,63 & 772,68 \\
Rendah & $(X<6,82)$ & 44 & & & 50,57 & 800,37 \\
\hline & Jumlah & 87 & - & - & 100 & - \\
\hline
\end{tabular}

Sumber : Data Primer Diolah, 2007.

Berdasarkan Tabel 2, diketahui bahwa pendidikan formal yang dimiliki oleh pemanen kelapa sawit PT. Socfindo Perkebunan Aek Loba berada pada kisaran 6-12 tahun dengan ratarata 7,9 tahun dan berada pada kategori rendah yaitu sebesar $50,57 \%$ yang menunjukkan bahwa pendidikan mereka masih relatif rendah. Kategori lama pendidikan tinggi produktivitas rata-ratanya 
sebesar $572,26 \mathrm{~kg} / \mathrm{hr}$, pada kategori lama pendidikan sedang dan rendah produktivitas rataratanya sebesar $772,68 \mathrm{~kg} / \mathrm{hr}$ dan $800,37 \mathrm{~kg} / \mathrm{hr}$.

\section{Pengalaman Kerja}

Pengalaman sebagai pemanen kelapa sawit akan sangat membantu tenaga kerja tersebut dalam mengambil keputusan pemanenan kelapa sawit. Pengambilan keputusan yang cepat mengenai pemanenan buah sawit yang sudah layak untuk dipanen akan mempengaruhi jumlah TBS yang akan ia dapatkan. Hal ini akan mempengaruhi jumlah produksi kelapa sawit yang dipanen.

Tabel 3. Pengalaman Kerja Pemanen Kelapa Sawit

\begin{tabular}{|c|c|c|c|c|c|c|}
\hline Kategori & $\begin{array}{l}\text { Lama kerja } \\
\text { (th) }\end{array}$ & $\begin{array}{l}\text { Jumlah } \\
\text { (org) }\end{array}$ & $\begin{array}{l}\text { Kisaran } \\
\text { (th) }\end{array}$ & $\begin{array}{l}\text { Rerata } \\
\text { (th) }\end{array}$ & $\begin{array}{c}\text { Persentase } \\
(\%)\end{array}$ & $\begin{array}{l}\text { Produktivitas } \\
\text { Rerata (kg/hr) }\end{array}$ \\
\hline Tinggi & $(X>9,23)$ & 24 & \multirow{3}{*}{$3-18$} & \multirow{3}{*}{7,46} & 27,59 & 1181,37 \\
\hline Sedang & $(5,69 \leq x \leq 9,23)$ & 32 & & & 36,78 & 761,85 \\
\hline Rendah & $(X<5,69)$ & 31 & & & 35,63 & 429,17 \\
\hline \multicolumn{2}{|r|}{ Jumlah } & 87 & - & - & 100 & - \\
\hline
\end{tabular}

Sumber : Data Primer Diolah, 2007

Berdasarkan Tabel 3, diketahui bahwa pengalaman kerja yang dimiliki oleh pemanen kelapa sawit PT Socfindo Perkebunaan Aek Loba berada pada kisaran 3 - 18 tahun dengan rata-rata 7,46 tahun dan persentase terbesar terdapat pada kategori sedang yaitu 32 orang atau sebesar 36,78. Hal ini menunjukkan bahwa pengalaman kerja pemanen kelapa sawit tersebut masih termasuk pada golongan sedang. Kategori pengalaman kerja tinggi produktivitas rata-ratanya sebesar $1181,37 \mathrm{~kg} / \mathrm{hr}$, pada kategori pengalaman kerja sedang dan rendah produktivitas rataratanya masing-masing sebesar $761,85 \mathrm{~kg} / \mathrm{hr}$ dan $429,17 \mathrm{~kg} / \mathrm{hr}$.

\section{Jumlah Tanggungan Keluarga}

Jumlah tanggungan keluarga akan mempengaruhi seseorang untuk giat bekerja untuk memenuhi kebutuhan hidup orang tersebut dan keluarganya. jumlah tanggungan keluarga akan 
memotivasi pemanen tersebut untuk lebih giat dalam bekerja untuk memenuhi kebutuhan hidupnya sekeluarga.

Tabel 4. Jumlah Tanggungan Keluarga Pemanen Kelapa Sawit

\begin{tabular}{lcccccc}
\hline Kategori & Tanggungan & $\begin{array}{c}\text { Jumlah } \\
\text { (org) }\end{array}$ & $\begin{array}{c}\text { Kisaran } \\
\text { (org) }\end{array}$ & $\begin{array}{c}\text { Rerata } \\
\text { (org) }\end{array}$ & $\begin{array}{c}\text { Persentase } \\
\text { (\%) }\end{array}$ & $\begin{array}{c}\text { Produktivitas } \\
\text { Rerata (kg/hr) }\end{array}$ \\
\hline Banyak & $(X>4,2)$ & 22 & & & 25,29 & 972,13 \\
Sedang & $(2,79 \leq X \leq 4,2)$ & 45 & $1-6$ & 3,49 & 51,72 & 781,66 \\
Sedikit & $(X<2,79)$ & 20 & & & 22,99 & 473,76 \\
\hline \multicolumn{2}{c}{ Jumlah } & 87 & - & - & 100 & - \\
\hline
\end{tabular}

Sumber : Data Primer Diolah, 2007.

Berdasarkan Tabel 4, diketahui bahwa jumlah tanggungan keluarga pemanen kelapa sawit PT. Socfindo Perkebunan Aek Loba berada pada kisaran 1 - 6 orang dan dengan rata-rata 3,49 orang dan persentase terbesar pada kategori sedang yaitu sebanyak 45 orang atau sebesar $51,72 \%$ Hal ini menunjukkan bahwa jumlah tanggungan keluarga pemanen kelapa sawit tersebut masih relatif sedang. Kategori tanggungan keluarga banyak produktivitas rata-ratanya sebesar $972,13 \mathrm{~kg} / \mathrm{hr}$, pada kategori tanggungan keluarga sedang produktivitas rata-ratanya sebesar $781,66 \mathrm{~kg} / \mathrm{hr}$ dan pada kategori tanggungan keluarga sedikit produktivitas rata-ratanya sebesar $473,76 \mathrm{~kg} / \mathrm{hr}$.

\section{Persepsi terhadap Premi}

Persepsi adalah proses bagaimana seseorang menyeleksi, mengatur dan menginterpretasikan masukan-masukan informasi untuk menciptakan gambaran keseluruhan yang berarti.

Tabel 5. Persepsi terhadap Premi Pemanen Kelapa Sawit

\begin{tabular}{cccc}
\hline Kategori & $\begin{array}{c}\text { Jumlah } \\
\text { (org) }\end{array}$ & $\begin{array}{c}\text { Persentase } \\
\text { (\%) }\end{array}$ & $\begin{array}{c}\text { Produktivitas } \\
\text { Rerata (kg/hr) }\end{array}$ \\
\hline Baik = 1 & 39 & 44,83 & 1033,43 \\
Buruk = 0 & 48 & 55,17 & 536,10 \\
\hline \multicolumn{1}{c}{ Jumlah } & 87 & 100 & - \\
\hline
\end{tabular}

Sumber : Data Primer Diolah, 2007. 
Pemanen kelapa sawit di PT Socfindo Perkebunan Aek Loba ada yang berpersepsi baik terhadap premi yang mereka terima dan ada juga yang persepsinya buruk terhadap premi tersebut. Berdasarkan Tabel 5, diketahui bahwa pemanen kelapa sawit PT Socfindo Perkebunan Aek Loba yang berpersepsi baik terhadap premi sebanyak 39 orang atau $44,83 \%$ dan yang berpersepsi buruk sebanyak 48 orang atau 55,17 \%. Hal ini menunjukkan bahwa persepsi terhadap premi pada pemanen kelapa sawit tersebut masih relatif buruk terhadap premi yang mereka terima. Kategori yang berpersepsi baik terhadap premi produktivitas rata-ratanya sebesar $1033,43 \mathrm{~kg} / \mathrm{hr}$, sedangkan kategori yang berpersepsi buruk produktivitas rata-ratanya sebesar $536,1 \mathrm{~kg} / \mathrm{hr}$.

\section{Motivasi Kerja}

Pemanen kelapa sawit yang memiliki motivasi kerja yang baik akan bersemangat dalam melakukan pekerjaannya, sehingga mampu memperoleh hasil panen yang optimal. Sebaliknya pemanen kelapa sawit yang memiliki motivasi yang buruk tidak akan mendapatkan hasil panen yang optimal, karena tidak memiliki keinginan yang kuat dalam mencari lebihan hasil panen.

Tabel 6. Motivasi Kerja Pemanen Kelapa Sawit

\begin{tabular}{lccc}
\hline \multicolumn{1}{c}{ Kategori } & $\begin{array}{c}\text { Jumlah } \\
\text { (org) }\end{array}$ & $\begin{array}{c}\text { Persentase } \\
(\mathbf{\%})\end{array}$ & $\begin{array}{c}\text { Produktivitas } \\
\text { Rerata (kg/hr) }\end{array}$ \\
\hline Baik $=1$ & 31 & 35,63 & 948,8 \\
Buruk $=0$ & 56 & 64,37 & 653,99 \\
\hline \multicolumn{1}{c}{ Jumlah } & 87 & 100 & - \\
\hline
\end{tabular}

Sumber : Data Primer Diolah, 2007.

Berdasarkan Tabel 6, diketahui bahwa pemanen kelapa sawit PT Socfindo Perkebunan Aek Loba yang memiliki motivasi kerja tinggi sebanyak 31 orang atau 35,63\% dan yang memiliki motivasi kerja rendah sebanyak 56 orang atau $64,37 \%$. Hal ini menunjukkan bahwa motivasi kerja pada pemanen kelapa sawit tersebut masih relatif buruk. Kategori yang motivasi kerja baik 
produktivitasnya rata-ratanya sebesar $948,8 \mathrm{~kg} / \mathrm{hr}$, sedangkan kategori yang motivasi kerja buruk produktivitas rata-ratanya sebesar $653,99 \mathrm{~kg} / \mathrm{hr}$.

\section{Produktivitas Pemanen Kelapa Sawit}

Peningkatan produktivitas tenaga kerja menurut Ravianto (1983) dalam Harsiwi (2004) dipengaruhi oleh beberapa faktor, baik yang berhubungan dengan tenaga kerja itu sendiri seperti motivasi dan keluarga, maupun faktor lain seperti pendidikan, keterampilan, disiplin, sikap dan etika kerja, motivasi, gizi dan kesehatan, tingkat penghasilan, jaminan sosial, lingkungan dan iklim kerja, teknologi, sarana produksi, manajemen dan kesempatan berprestasi.

Hasil penelitian menunjukkan dari rata-rata umur tanaman kelapa sawit 15 tahun produktivitas pemanen kelapa sawit di PT Socfindo berada pada kisaran 93,05-1884,8 dengan rerata $759,04 \mathrm{~kg} / \mathrm{hr}$.

Tabel 7. Produktivitas Pemanen Kelapa Sawit

\begin{tabular}{lccccc}
\hline Kategori & $\begin{array}{c}\text { Produktivitas } \\
(\mathbf{K g} / \mathbf{h r})\end{array}$ & Jumlah (org) & $\begin{array}{c}\text { Kisaran } \\
(\mathbf{K g})\end{array}$ & $\begin{array}{c}\text { Rerata } \\
(\mathbf{K g})\end{array}$ & $\begin{array}{c}\text { Persentase } \\
(\%)\end{array}$ \\
\hline Tinggi & $(\mathrm{X}>987,39)$ & 25 & & & 28,74 \\
Sedang & $(530,69 \leq X \leq 987,39)$ & 29 & $93,05-1884,8$ & 759,04 & 33,33 \\
Rendah & $(X<530,69)$ & 33 & & & 37,93 \\
\hline & Jumlah & 87 & - & - & 100 \\
\hline
\end{tabular}

Sumber : Data Primer Diolah, 2007.

Tabel 7 menunjukkan bahwa $28,74 \%$ dari pemanen kelapa sawit telah memiliki produktivitas tinggi dan 37,93 \% memiliki produktivitas rendah, serta 33,33\% memiliki produktivitas sedang. Dari rincian tersebut, dapat disimpulkan bahwa produktivitas pemanen kelapa sawit di PT. Socfindo Perkebunan Aek Loba masih tergolong rendah.

\section{Analisis Faktor-faktor yang Mempengaruhi Produktivitas Pemanen}

Untuk mengetahui pengaruh umur, pengalaman kerja, jumlah tanggungan keluarga, persepsi terhadap upah dan motivasi kerja terhadap produktivitas pemanen kelapa sawit di PT. Socfindo Perkebunan Aek Loba dapat dilihat pada Tabel 8. 
Tabel 8. Hasil Estimasi Faktor-faktor yang Mempengaruhi Produktivitas Pemanen Kelapa Sawit pada PT. Socfindo Perkebunan Aek Loba

\begin{tabular}{lccc}
\hline \multicolumn{1}{c}{ Variabel Bebas } & Koef. Regresi & Std Error & t hitung \\
\hline Umur (X1) & 22,274 & 8,191 & $2,719^{*}$ \\
Pengalaman kerja (X2) & 56,086 & 12,173 & $4,608^{*}$ \\
Jumlah Tanggungan Keluarga (X3) & 54,719 & 25,752 & $2,125^{*}$ \\
Persepsi terhadap Premi (D1) & 107,484 & 73,520 & 1,462 \\
Motivasi kerja (D2) & 11,329 & 68,531 & 0,165 \\
\hline Constant $=-684,144$ & & & \\
Adjusted R2 $=\quad 0,634$ & & & \\
F hitung $=30,788$ & & & \\
$t$ tabel $=1,66$ & & & \\
$\mathrm{~F}$ tabel $=$ & & & \\
\hline
\end{tabular}

Sumber : Data Primer Diolah, 2007

Keterangan $\left({ }^{*}\right)=$ Berpengaruh nyata pada taraf kepercayaan $95 \%$

Berdasarkan hasil regresi diatas, dapat ditulis suatu persamaan sebagai berikut :

$$
Y=-684,144+22,274 X_{1}+56,086 X_{2}+54,719 X_{3}+107,484 D_{1}+11,329 D_{2}
$$

Dari hasil estimasi, dapat diketahui bahwa koefisien determinasi Adjusted $\mathrm{R}^{2}$ adalah 0,634. Hal ini berarti $63,4 \%$ variasi dari produktivitas dapat dijelaskan oleh variabel umur, pengalaman kerja, jumlah tanggungan keluarga, persepsi terhadap premi dan motivasi kerja. Sedangkan sisanya 36,6 \% dipengaruhi oleh faktor lain yang tidak dimasukkan dalam model regresi, misalnya musim dan perlakuan pada tanaman.

Pengujian pengaruh variabel $\mathrm{X}$ secara bersama-sama terhadap variabel terikat digunakan uji F. Hasil uji F menunjukkan bahwa $F$ hitung $(+30,788)$ lebih besar dari pada $F$ tabel $(+2,33)$ pada taraf kepercayaan $95 \%$.

\section{$\operatorname{Umur}\left(\mathrm{X}_{1}\right)$}

Dari hasil regresi diketahui bahwa variabel umur $\left(X_{1}\right)$ memiliki tanda positif terhadap produktivitas dengan nilai koefisien regresi sebesar 22,274 . Dikarenakan umur pemanen berada pada 21 - 47 tahun (umur produktif) maka dapat dikatakan bertambahnya umur 1 tahun, akan 
meningkatkan produktivitas sebesar $22,274 \mathrm{~kg} / \mathrm{hari}$, dengan anggapan variabel bebas lainnya konstan. Variabel umur $\left(X_{1}\right)$ memiliki nilai t hitung $(2,719)$ lebih besar dari nilai t tabel $(1,66)$, dengan demikian Ho ditolak dan Ha diterima. Artinya umur pemanen kelapa sawit mempengaruhi produktivitas kerja pemanen kelapa sawit di PT Socfindo Perkebunan Aek Loba.

\section{Pengalaman Kerja $\left(\mathbf{X}_{2}\right)$}

Dari hasil regresi diketahui bahwa variabel pengalaman kerja $\left(\mathrm{X}_{2}\right)$ memiliki tanda positif terhadap produktivitas dengan nilai koefisien regresi sebesar 56,086. Koefisien regresi tersebut menyatakan bahwa setiap bertambahnya pengalaman kerja 1 tahun, akan meningkatkan produktivitas sebesar 56,086 kg/hari, dengan anggapan variabel bebas lainnya konstan. Variabel pengalaman kerja $\left(X_{2}\right)$ memiliki nilai $t$ hitung $(4,608)$ lebih besar dari nilai $t$ tabel $(1,66)$, dengan demikian Ho ditolak dan Ha diterima. Artinya pengalaman kerja pemanen kelapa sawit mempengaruhi produktivitas kerja pemanen kelapa sawit di PT Socfindo Perkebunan Aek Loba.

\section{Jumlah Tanggungan Keluarga $\left(\mathrm{X}_{3}\right)$}

Dari hasil regresi diketahui bahwa variabel jumlah tanggungan keluarga $\left(\mathrm{X}_{3}\right)$ memiliki tanda positif terhadap produktivitas dengan nilai koefisien regresi sebesar 54,719 . Koefisien regresi tersebut menyatakan bahwa pertambahan jumlah anggota keluarga 1 orang, akan meningkatkan produktivitas sebesar $54,719 \mathrm{~kg} / \mathrm{hari}$, dengan anggapan variabel bebas lainnya konstan. Variabel jumlah tanggungan keluarga $\left(X_{3}\right)$ memiliki nilai t hitung $(2,125)$ lebih besar dari nilai t tabel $(1,66)$, dengan demikian Ho ditolak dan Ha diterima. Artinya jumlah tanggungan kelurga pemanen kelapa sawit mempengaruhi produktivitas kerja pemanen kelapa sawit di PT Socfindo Perkebunan Aek Loba.

\section{Persepsi terhadap Premi $\left(D_{1}\right)$}

Persepsi pemanen kelapa sawit terhadap premi ada yang berkategori baik (1) dan ada yang berkategori buruk (0). Persepsi pemanen kelapa sawit di PT. Socfindo Perkebunan Aek Loba 
terhadap premi dominan buruk, karena dari hasil regresi variabel persepsi terhadap premi $\left(D_{1}\right)$ memiliki nilai t hitung $(1,462)$ lebih kecil dari nilai $t$ tabel $(1,66)$, dengan demikian Ho diterima dan Ha ditolak. Artinya tidak ada perbedaan nyata antara produktivitas pemanen yang memiliki persepsi terhadap premi yang baik dengan pemanen yang memiliki persepsi terhadap premi yang buruk.

\section{Motivasi Kerja $\left(D_{2}\right)$}

Motivasi kerja pemanen kelapa sawit ada yang berkategori baik (1) dan ada yang berkategori buruk (0). Motivasi kerja pemanen kelapa sawit di PT Socfindo Perkebunan Aek Loba dominan buruk, karena dari hasil regresi variabel motivasi kerja $\left(D_{2}\right)$ diketahui nilai t hitung $(0,165)$ lebih kecil dari nilai t tabel $(1,66)$, dengan demikian Ho diterima dan Ha ditolak. Artinya tidak ada perbedaan nyata antara produktivitas pemanen yang memiliki motivasi kerja yang baik dengan pemanen yang memiliki motivasi kerja yang buruk.

\section{KESIMPULAN DAN SARAN}

Dari pembahasan di atas, maka dapat ditarik kesimpulan sebagai berikut:

1. Tingkat produktivitas pemanen kelapa sawit pada PT. Socfin Indonesia Perkebunan Aek Loba mayoritas rendah yaitu pada kategori kurang dari $530,5 \mathrm{Kg} / \mathrm{hr}$ dan produktivitas rata-rata sebesar 759,04 Kg/hr.

2. Faktor-faktor yang mempengaruhi produktivitas pemanen kelapa sawit pada PT Socfin Indonesia Perkebunan Aek Loba adalah umur, pengalaman kerja, jumlah tanggungan keluarga. Sedangkan faktor persepsi terhadap premi dan motivasi kerja tidak mempengaruhi produktivitas pemanen kelapa sawit pada PT Socfin Indonesia Perkebunan Aek Loba.

Berdasarkan pembahasan di atas perlu disarankan bahwa perusahaan hendaknya memberikan pelatihan-pelatihan kepada pemanen dalam hal peningkatan ketrampilan pemanen 
dalam memanen kelapa sawit. Hal ini bertujuan agar pemanen mampu memperoleh produktivitas kerja yang tinggi.

\section{DAFTAR PUSTAKA}

Indrawati dan Richard Von Liewelyn. 1999. Pengujian Model Regresi untuk Pengukuran Produktivitas Tenaga Kerja: Kasus Industri Kecil di Jawa Tengah. http://puslit.petra.ac.id/journals/management/ (diakses pada tanggal 9 Januari 2008)

Mardiana. 2001. Faktor-faktor Penentu Tingkat Produktivitas Pemanen Sawit (Studi Kasus pada PT. Agromuko Estate Air Dikit Kecamatan Mukomuko Utara Kabupaten Bengkulu Utara). Skripsi Jurusan Sosial Ekonomi Pertanian, Fakultas Pertanian, Universitas Bengkulu. Bengkulu. (Tidak dipublikasikan)

Umar H. 2003. Riset Sumber Daya Manusia Dalam Organisasi. Gramedia Pustaka Utama. Jakarta. 